\title{
O ENSINO DA LÍNGUA PORTUGUESA A PARTIR DE GÊNEROS DISCURSIVOS NO GESTAR II ${ }^{1}$
}

\author{
PORTUGUESE TEACHING THROUGH DISCURSIVE GENRES \\ ON GESTAR II
}

\author{
Luci Schmoeller \\ Mestranda em Lingüística - Universidade Federal de Santa Catarina
}

\begin{abstract}
Resumo
Nos últimos anos, o ensino de textos, nas aulas de língua portuguesa, sofreu grandes transformações. Essas mudanças foram incorporadas pelo PCN de língua portuguesa e em 2009 é recomendado nas escolas o ensino de textos através da teoria de Bakhtin sobre gêneros discursivos, que analisa um texto através de sua função social, seu contexto de produção na interação dos sujeitos, suas regularidades, entre outros aspectos. Contudo, sem a formação adequada do professor, essas mudanças se tornam inócuas. Por isso, o MEC está oferecendo um curso de formação docente, GESTAR II. O presente artigo é o resultado da análise do material didático utilizado no curso, quanto à aplicação de gêneros discursivos no ensino da língua portuguesa. A análise fundamenta-se nos estudos de Marquesi (1992); Zanettin (1992); Furlanetto (2002); Biasi-Rodrigues (2002) e Antunes (2002) e na teoria de gêneros do discurso do círculo de Bakhtin.
\end{abstract}

Palavras-chave: Gêneros discursivos. Ensino. Formação docente. GESTAR II.

\begin{abstract}
Over the last years, texts' teaching, in Portuguese lessons, has changed. Those changes were part of PCN and, today, texts teaching based on Bakhtin theory about speech genres is advisable in schools. However, without adequate teacher instruction those changes become ineffective. Thus, MEC is offering a course for teachers' instruction, GESTAR II. This article is result of GESTAR II educational material analysis. The analysis is based on studies developed by Marquesi (1992); Zanettin (1992); Furlanetto (2002); Biasi-Rodrigues (2002) e Antunes (2002) and on the speech genres theory from Bakhtin circle.
\end{abstract}

Keywords: Speech genres. Teaching. Teachers’ formation. GESTAR II.

\section{INTRODUÇÃO}

Nos últimos anos, a reflexão acerca da produção textual na sociedade tem gerado diversas modificações no ensino de língua portuguesa. A escola, nos níveis fundamental e médio, vem tentando trabalhar didaticamente essa questão, embora ainda haja predomínio da noção de tipologia textual, reflexo do estruturalismo predominante dos anos 50 e 60. A lingüística passa a se dedicar, também, à questão das tipologias textuais,

\footnotetext{
${ }^{1}$ Este trabalho foi desenvolvido na disciplina de Linguística Geral (UFSC) no programa de mestrado em Lingüística.
} 
embora desvinculadas da noção de gênero (cf. MEURER; MOTTA-ROTH, 2002, p.1925)

Sabe-se que a noção de tipologia textual foi bastante forte nas décadas de 70, 80 e parte da década de 90, e descrevia superestruturas textuais. A análise (Crítica) do Discurso e outras correntes teóricas que surgiram a partir da década de 80 trouxeram à tona a noção de gênero discursivo, baseando-se no pensamento bakhtiniano. No Brasil, essas modificações foram aceitas e incorporadas aos Parâmetros Curriculares Nacionais de língua portuguesa - doravante PCN- proposto pelo MEC. A abordagem sóciointeracionista do PCN prevê o desenvolvimento de competências comunicativas, portanto, o ensino de língua materna não pode estar fechado a estruturas tipológicas às quais o aluno tem de se adaptar.

Procurando renovar o ensino de língua portuguesa para adequá-lo aos aspectos postulados pelo PCN, o MEC, neste ano de 2009, está oferecendo um curso de formação continuada para professores dos anos finais do ensino fundamental da rede pública de ensino. Mas, será que o material utilizado para a capacitação desses professores aborda a noção de gêneros discursivos e seus usos no cotidiano do aluno? De que forma?

O presente artigo tem como propósito apresentar a avaliação do material didático utilizado neste curso, intitulado Programa Gestão da Aprendizagem Escolar, doravante GESTAR II, quanto à abordagem da teoria de Bakhtin sobre gêneros discursivos. Este material serve de apoio ao professor para planejamento das aulas, oferecendo uma base teórica e sugestões de atividades relacionadas ao ensino da língua portuguesa.

\section{SOBRE O ENSINO DE TEXTOS}

Sabe-se que o ensino da redação a partir da noção de tipologia textual é limitante e não dá o devido destaque ao papel dos sujeitos em interação através de um processo de enunciação e, portanto, não pode desenvolver as competências comunicativas prezadas pelo PCN e pela Proposta Curricular de Santa Catarina.

É provável que a prática dos professores de língua materna, em se tratando da produção textual, ainda esteja centrada na abordagem tipológica. Supõe-se que as aulas de redação que partem dos textos presentes no cotidiano dos alunos, tais como aqueles pertencentes aos discursos da mídia, da música, do cinema e da literatura, se dêem de forma bastante tímida e pouco consciente do processo enunciativo, apesar de alguns livros didáticos, utilizados pelas escolas estaduais, privilegiarem esses textos.

Os professores devem estar aptos a fazer emergir, para a superfície do texto lido ou a ser produzido, a estreita ligação entre quem e o que se quer dizer, para quem se quer dizer, com que intenção e em que momento, especialmente nos níveis fundamental e médio quando o aluno estará se construindo enquanto sujeito em sentido amplo, quando todas as possibilidades estão à sua disposição. É nesse momento que a ele deve ser oportunizado o desenvolvimento das mais variadas competências comunicativas.

Para tal, é preciso atenção à formação dos professores de língua portuguesa. Para que possam refletir sobre seu papel na educação, como um dos sujeitos no processo de 
ensino aprendizagem; perceber e refletir sobre os textos quanto aos aspectos discursivos, enunciativos e cognitivos a partir das linguagens verbal e não-verbal; assumir o texto como materialidade do discurso; abordar uma reflexão sobre o uso morfológico e sintático da língua, a partir de seu processo de produção; abordar os diferentes papéis sociais que os sujeitos assumem no momento da interação comunicativa, a reflexão sobre a posição ocupada pelos sujeitos e o momento históricosocial-cultural-ideológico em que está inserido.

Entende-se que, a prática de ensino da produção textual deve ser desenvolvida de forma que:

a) Os textos - suas regularidades, suas normas, suas convenções de ocorrência - sejam objeto de estudo das aulas de língua;

b) Os textos sejam usados em situação concretas de interação, implicando sujeitos em contextos que exijam determinados gêneros;

c) As regras lingüísticas tenham funcionalidade, pois serão definidas de acordo com as particularidades de cada gênero em cada situação;

d) $\mathrm{O}$ ensino proporcione o desenvolvimento de habilidades comunicativas, tanto para a fala como para a escrita, e contemplem a variedade de textos que, de fato, marca a vida das pessoas nos grupos sociais.

\section{OS GÊNEROS DISCURSIVOS}

A lingüística textual desenvolveu discussões em torno da produção textual, em especial da tipologia textual. Várias pesquisas foram realizadas no Brasil no sentido de classificar as tipologias da narração, da descrição e da argumentação, tais como as de Marquesi (1992) e Zanettin (1992). O conceito de gêneros discursivos passou a ser abordado a fim de dar conta da produção textual a partir da década de 80 , trazendo um enfoque sócio-interacionista ao tema.

A noção de gênero discursivo proposto por Bakhtin (1953) é um instrumento de construção do letramento escolar que permite agir eficazmente em situações sociais de comunicação. Segundo Bakhtin (1953, p. 279), cada grupo social em sua época possui um conjunto de formas de discurso (gêneros do enunciado) que reflete a realidade ou 0 cotidiano em transformação. Nesse sentido, as mudanças sociais se refletem até nas normas (relativamente estáveis) dos enunciados.

A inesgotabilidade das atividades humanas nas suas diversas e variadas esferas resultam na heterogeneidade e complexidade dos gêneros. À medida que essas atividades vão se ampliando e se modificando, os gêneros vão se diversificando.

Bakhtin classifica os gêneros do discurso em Gêneros Primários (simples) e Gêneros Secundários (complexos).

Os gêneros primários se referem ao cotidiano imediato, à situação imediata em que são produzidos e onde a atividade humana se realiza. Textos desse tipo vão ser compreendidos em relação com o contexto e, nesse processo, o locutor tem um autocontrole do enunciado, podendo fazer as escolhas de acordo com sua função. São exemplos de gêneros primários: certos tipos de diálogo oral, cotidianos e familiares, que 
se referem à realidade social mais imediata, diálogos das reuniões sociais, dos círculos de amigos e familiares, dos companheiros de serviço, etc. (ibidem, p. 285)

Os gêneros secundários (literários, científicos, jornalísticos), que absorvem e transformam os gêneros primários, são geralmente produzidos de forma escrita, por sua vez, distanciam-se da situação imediata e cotidiana de produção e se referem a uma esfera de dimensão cultural mais complexa e mais evoluída. Segundo Bakhtin (1953):

Os gêneros secundários do discurso - o romance, o teatro, o discurso científico, o discurso jornalístico, etc. - aparecem em circunstâncias de uma comunicação cultural mais complexa e relativamente mais evoluída, principalmente escrita: artística, científica, sociopolítica. (ibidem, p. 281).

É através dos gêneros discursivos que se estrutura o discurso. Contudo, não é sujeito que cria o gênero, eles são dados socialmente, pela cultura. As manifestações linguísticas são organizadas em determinados gêneros desde o momento em que a criança começa a falar. E ela vai aprendendo a utilizar a linguagem no processo de enunciação, adequando seus enunciados em gêneros a diferentes situações de comunicação.

Há inúmeras formas de gêneros, disponíveis na sociedade, pois há grande diversidade de situações de comunicação em diferentes esferas da atividade humana.

Nesta perspectiva, no momento da enunciação, o locutor faz o movimento de escolha do gênero, determinada pela situação de comunicação. Esse movimento é de importante subjetividade dentro da formação linguística do locutor.

Portanto, para Bakhtin, os gêneros funcionam no contexto de uma interação (verbal/social):

Aprendemos a moldar nossa fala às formas do gênero e, ao ouvir o falado por outro, sabemos de imediato, bem nas primeiras palavras, pressentir-lhe o gênero, adivinhar-lhe o volume (a extensão aproximada do todo discursivo), a dada estrutura composicional, prever-lhe o fim, ou seja, desde o início, somos sensíveis ao todo discursivo que, em seguida, no processo da fala, evidenciará suas diferenciações (ibidem, p.302).

Bakhtin postula também que, para haver comunicação verbal, tem que haver gêneros discursivos, além da elaboração sintática e estilística. O falante dispõe, além das formas da língua (recursos linguísticos) das formas dos enunciados (construção composicional baseado em um gênero) na comunicação discursiva do conteúdo cujos sentidos determinam as escolhas que o sujeito concretiza:

Para falar utilizamo-nos sempre dos gêneros do discurso, em outras palavras, todos os nossos enunciados dispõem de uma forma padrão e relativamente de estruturação e um todo. Possuímos um rico repertório dos gêneros do discurso orais (e escritos). Na prática, usamo-los com segurança e destreza, mas podemos ignorar totalmente a sua existência teórica.[...]...falamos em vários gêneros sem suspeitar de sua 
existência.[...] As formas da língua e as formas típicas de enunciados, isto é, os gêneros do discurso, introduzem-se em nossa experiência e em nossa consciência conjuntamente e sem que sua estreita correlação seja rompida. Aprender a falar é aprender a estruturar enunciados (porque falamos por enunciados e não por orações isoladas e, menos ainda, é óbvio, por palavras isoladas). Os gêneros do discurso organizam nossa fala da mesma maneira que a organizam as formas gramaticais (sintáticas) (ibidem, p. 301-302).

Então, se a organização da linguagem é dada através de gêneros e estes são convencionados socialmente, associados a contextos culturais, históricos e institucionais, são nesses ambientes em que se dá a interação verbal. E a escola é o espaço em que se dá a transformação da linguagem oral e escrita do sujeito. O domínio da grafia não se resume ao uso dos grafemas, é uma nova forma de comunicar-se, e deve ser visto como uma nova prática social em que o sujeito se torna autônomo para utilizar a escrita como atividade discursiva, de acordo com suas necessidades e dentro das situações de interação em que ele está inserido.

Furlanetto (2002) afirma que:

Os gêneros, tais como delineados por Bakhtin, se apresentam como tipos específicos de enunciados, recorrentes em situações características, uma vez que associados a esferas da sociedade, seja em linguagem cotidiana, seja em linguagem mais ou menos formal. Em princípio, as manifestações verbais se dão na forma de um gênero de discurso (alguns dirão de fala, ou de texto), que são marcados não só tematicamente como na forma de sua organização e de seu estilo (Ibidem: p. 77).

O PCN, segundo a autora, postula que o texto deve ser objeto de ensino privilegiado e deve ser visto como forma discursiva que reflete a diversidade de gêneros recorrentes na sociedade. O PCN apresenta como objetivo geral criar condições para que o aluno possa desenvolver sua competência discursiva -"Competência discursiva refere-se a um 'sistema de contratos semânticos' responsável por uma espécie de 'filtragem' que opera os conteúdos em dois domínios interligados que caracterizam o dizível: o universo intertextual e os dispositivos estilísticos acessíveis à enunciação dos diversos discursos" (PCN, 1997).

Biasi-Rodrigues (2002) questiona se os preceitos do PCN são obedecidos, pois inúmeros livros didáticos do ensino fundamental propõem atividade a partir da noção de gêneros, mas nem sempre as propostas contemplam realmente o desenvolvimento de competências comunicativas ou a efetiva relação entre teoria e prática. Muitas vezes é o velho estruturalismo com roupagem de sócio-interacionismo.

Antunes (2002), discorrendo acerca das mudanças na disciplina de língua portuguesa, postula que, neste contexto, entrava em jogo, para os professores, uma mudança de perspectiva, que afetaria sua concepção de língua, de gramática, de texto, assim, a redefinição do objeto de ensino e:

Passar das discussões - muitas delas altamente especializadas, aprovadas pelo fato de circularem entre os pares da academia - à 
prática pedagógica solicitava repensar, redimensionar e refazer as perspectivas e os paradigmas anteriores, tarefa que, sozinhos, os professores do ensino fundamental e do ensino médio não conseguiam fazer (ibidem, p. 71).

A tentativa de usar a "gramática" a partir dos textos gerou situações de usar o texto como pretexto. Assim, lança-se mão de um texto, faz-se a famosa "interpretação”, os alunos falam, fazem debates, encenam e, depois disso, as frases são retiradas do texto para a verificação de itens gramaticais dentro da mais perfeita tradição gramatical.

\section{SOBRE A FORMAÇÃO DOCENTE}

Sobre a prática pedagógica, a Proposta Curricular de Santa Catarina (1998) afirma:

O professor deve ser um mediador no acesso ao conhecimento das relações sociais, as quais não se manifestam explicitamente. Para tanto se faz necessário que em sua formação-ação tenham adquirido aguda consciência da realidade e sólida fundamentação teórica que lhes permita interpretar e direcionar essa realidade, além de suficiente instrumentação técnica para nela intervir (Ibidem, p. 85).

As sugestões para a prática de formação permanente do professor são contempladas na Proposta Curricular de Santa Catarina (1998): se o aluno pode e deve aprender, o professor também deve estar em constante processo de aprendizado, seja antes ou durante o seu trabalho. O aprendizado é permanente. Para que a questão educacional seja tratada com seriedade, é necessária a formação permanente do professor, sob pena de que toda a proposta se torne inócua (ibidem, p. 88).

Sugere uma série de práticas de formação continuada:

a) encontros de estudo teórico/relação com a prática;

b) elaboração de um projeto pedagógico para a escola;

c) elaboração de projetos específicos das áreas, considerando as possibilidades de trabalho interdisciplinar;

d) encontros para problematizar (relatos);

e) levantamento de questões instigadoras;

f) busca conjunta de referências para dar conta da investigação em pauta;

g) registro de atividades e avaliação;

h) avaliação periódica;

i) divulgação.

No senso comum, tem-se a máxima que toda mudança se faz pela educação, logo, a prática pedagógica é a base da transformação da sociedade e os professores seus agentes. É relevante considerar a estreita relação de reciprocidade entre "língua” e "sociedade" (a língua supõe a existência da comunidade e a comunidade requer a existência da língua). Estar bem preparado para mediar o aluno na aquisição da sua capacidade lingüística é o ponto crucial desta transformação. 


\section{ANÁLISE DO MATERIAL DIDÁTICO DO CURSO GESTAR II}

O Programa Gestão da Aprendizagem Escolar oferece formação continuada em língua portuguesa e matemática aos professores dos anos finais (do sexto ao nono ano) do ensino fundamental em exercício nas escolas públicas. A formação possui carga horária de 300 horas, sendo 120 horas presenciais e 180 horas a distância (estudos individuais) para cada área temática. O programa inclui discussões sobre questões prático-teóricas e busca contribuir para o aperfeiçoamento da autonomia do professor em sala de aula.” (www.mec.gov.br $>$ Educação Básica > PDE GESTAR II . acesso em 11/08/2009).

O Gestar I e II foi desenvolvido em conjunto pelo Ministério da Educação/MEC, Fundo Nacional de Desenvolvimento da Educação/FNDE e Secretarias Estaduais e Municipais de Educação. O Programa é um conjunto de ações pedagógicas, que incluem discussões sobre questões prático-teóricas.

O professor em formação (cursista) tem vários materiais de apoio:

a) 6 Cadernos de Teoria e Prática - TP;

b) 6 Cadernos de Apoio à Aprendizagem do Aluno -AAA - versão do professor;

c) 6 Cadernos de Apoio à Aprendizagem do Aluno -AAA - versão do aluno (para uso do professor).

A análise apresentada neste artigo deteve-se ao $3^{\circ}$ Caderno de Teoria e Prática - TP3material que fornece a base teórica do tema tratado, além de diversas atividades de interpretação, análise e discussão para que o professor exercite o que aprendeu na teoria.

\subsection{Caderno de Teoria e Prática - TP3}

\subsubsection{TP3: Gêneros e tipos textuais}

\section{Autora: Maria Luisa Monteiro Sales Coroa}

A autora introduz seu material dirigindo-se aos professores e explicando os objetivos e disposições do conteúdo a serem estudados. Explica que, para fins didáticos, há uma divisão das unidades entre o texto como atuação social e o texto como organização de informações, apesar de reconhecer que essas dimensões estão intimamente interrelacionadas. Observa também que a abordagem a respeito do ensino de textos que o material traz pode causar estranhamento, uma vez que a prática docente não tem familiaridade com a teoria de gêneros (COROA apud BRASIL, 2008, p. 14).

A primeira seção começa resgatando o conhecimento intuitivo sobre gêneros textuais e propõe a reflexão sobre o uso de determinados gêneros antes mesmo de aprendê-los na escola. Para isso, apresenta uma biografia, uma receita e uma propaganda, que contêm texto verbal e não-verbal. Depois de fazer algumas perguntas acerca das características de cada exemplo textual, informa que o que se acabou de fazer é reconhecer os gêneros 
textuais, mostrando que o conhecimento de mundo dá subsídios para o reconhecimento de diversos tipos de texto. Classifica essa capacidade de perceber as diferenças de competência sociocomunicativa. Em seguida, leva à reflexão de que o ato de escrever é também permeado pela noção de gêneros e que apreender suas características leva à escrita adequada. O texto oral também é abordado na primeira seção. O material propõe a reflexão sobre a finalidade dos textos orais. As atividades de verificação da aprendizagem, propostas pela autora, levam à produção de uma biografia contendo as características da biografia apresentada.

A seção 2 mostra como os textos se relacionam com seu contexto de produção e como o reconhecimento deste fator leva ao desenvolvimento da competência sóciocomunicativa.

"São as características que definem o uso de um determinado gênero" (COROA apud BRASIL, 2008, p. 29). A autora explica como o contexto, o nível de linguagem, o jogo do que está explícito ou implícito, as relações entre os interlocutores definem se um texto é adequado ou não. (2008, p. 29)

O material propõe uma atividade de produção de um bilhete a um colega, pedindo um livro emprestado, e um requerimento à escola, solicitando matrícula, discute acerca das diferenças dos textos, embora tratem de pedidos, e sobre as escolhas linguísticas que são feitas para um e para o outro momento: "Não apenas escolhemos as palavras e as frases para compor um texto, como também "escolhemos” o gênero em que vamos realizar esse texto. E o mais interessante é que muitas vezes sabemos escolher esse gênero sem ao menos ter aprendido isso na escola. Sabemos isso, porque desenvolvemos esse conhecimento junto com nossa intuição lingüística”. (COROA apud BRASIL, 2008, p. 31)

A autora não deixa de alertar para a inconstância dos gêneros, apesar de seguirem um certo padrão de organização: "Gêneros textuais não são estáticos: a longo prazo, são suscetíveis às alterações históricas, culturais e sociais no seio das quais se realizam; a curto prazo, podem ter as marcas de estilo dos sujeitos que os produzem".(COROA apud BRASIL, 2008, p. 32)

A seguir, aborda as características presentes nos gêneros, isto é, as regularidades que levam à classificação dos gêneros com tal. Para isso, apresenta a transposição de gêneros e discute a classificação, embora tenha as características de um gênero, em outro com outra finalidade.

Para o reconhecimento do padrão de organização dos gêneros, são apresentadas duas versões da fábula da Cigarra e a Formiga, escritas por Monteiro Lobato. As características comuns às duas versões são elencadas, além da intenção do autor em utilizar o mesmo gênero para abordar pontos de vista diferentes: "Cada texto só admite classificação após a análise de todos os fatores que envolvem sua construção: a estrutura lingüística, as finalidades do texto e a situação social dos interlocutores.” (COROA apud BRASIL, 2008, p. 42).

A Primeira unidade termina trazendo uma literatura que serve de base teórica aos professores: Luiz Antônio Marcuschi (2002) aborda a questão da relação entre os 
gêneros e as práticas sociais, dando base sólida para o professor em formação (COROA apud BRASIL, 2008, p. 45).

A próxima unidade, entitulada “Trabalhando com os gêneros textuais”, aborda a classificação do texto quanto à literariedade.

A Seção 1 enfatiza a finalidade estética da produção literária, contrapondo com a finalidade funcional do discurso científico. A autora sugere atividades com jornal: artigo jornalístico, classificados, poema, horóscopo. Os alunos deverão analisar os textos definindo como as informações estão organizadas, sua finalidade e seus leitores em potencial.

A seção 2 aborda somente o gênero poético e suas características. Apresenta diversos poemas e músicas sobre o mesmo tema e leva à reflexão sobre a finalidade destes textos, quem escreve e para quem se dirigem.

A seção 3 apresenta o cordel e suas características, mostrando que ainda cabem subclassificações dos textos dentro do gênero poesia. E mais uma vez, o contexto de produção é abordado.

Na unidade subsequente, a abordagem de textos de caráter informacional leva à classificação de tipos textuais, como as conhecidas narração e dissertação. Os tipos são conceituados e classificados contrapondo com a classificação de gêneros. A partir disso, foi feita uma reflexão desta correlação, além da transposição de um gênero para outro:

O texto se constrói estabelecendo significados em determinados contextos. Como significados estão ligados ao conhecimento de mundo que cada um de nós tem e esses significados se tecem no texto, é pelo estudo e pela prática de textos que podemos aprimorar nosso desempenho linguístico. E é também pelo estudo e pela prática de textos que seus alunos poderão ser bem-sucedidos no desempenho lingüístico.Tipos e gêneros textuais devem, assim, ser vistos, nestes cadernos, como classificações que não se sustentam sozinhas, mas como procedimentos de análise que juntos esclarecem sobre os mecanismos textuais (COROA apud BRASIL, 2008, p.13).

As seções 1, 2 e 3 desenvolvem a narração, descrição e dissertação, através de textos literários e não-literários, enfatizando o fim a que se destina cada tipo de texto. Sugere diversas atividades de produção de texto.

Em suma, uma vez que analisa os textos quanto às suas funções culturais e sociais e os classifica em gêneros - utiliza vários exemplos: biografias, receitas, fábulas propagandas, artigos jornalístico, classificados, literatura de cordel, etc -; as regularidades encontradas em textos de mesmo gênero são abordadas de forma clara e objetiva; a competência sociocomunicativa também é enfatizada; oferece base teórica sobre o tema; propõe roteiros de atividades concretas e bem planejadas - requisitos necessários para o ensino eficiente, abordados na seção 2 deste artigo -, o material de formação continuada do GESTAR II pode ser considerado um grande apoio à prática docente no ensino de textos e um agente de transformação do ensino da língua materna. 


\section{CONSIDERAÇÕES FINAIS}

O objetivo deste trabalho foi analisar o material do curso GESTAR II quanto à abordagem da teoria de Bakhtin a respeito dos gêneros do discurso, uma vez que o PCN de Língua Portuguesa sugere essa teoria como prática escolar para o desenvolvimento da competência linguística do aluno.

O resultado da análise do material, realizada no caderno de teoria e prática - TP3 - do curso GESTAR II, aponta para uma formação positiva e completa dos professores, em se tratando do ensino de gêneros discursivos nos últimos ciclos do ensino fundamental.

É notório que a teoria de gêneros foi contemplada satisfatoriamente, pois oferece uma base teórica sólida aos professores - leva-os a refletir sobre o uso de textos dentro de situações sociais, as regularidades presentes nos textos e sua efemeridade, os objetivos do sujeito ao usá-los para interagir com o outro - e sugere uma série de atividades a serem aplicadas em sala de aula, com os alunos, em situações concretas e coerentes.

Pôr em prática todos estes conceitos aprendidos é o mais importante, para que se trilhe o caminho de uma efetiva mudança no ensino de língua portuguesa. É importante que a formação continuada do professor permaneça em pauta nas Secretarias de Educação e que cada vez mais professores possam entrar em contato com as novas teorias de ensino de gêneros discursivos.

\section{REFERÊNCIAS}

ANTUNES, Irandré Costa. Língua, uso lingüístico e ensino. Perspectiva. Florianópolis, v. 20, n.1, p. 65-76, 2002.

BAKHTIN, Mikhail. Os gêneros do discurso. In: Estética da criação verbal.

São Paulo: Martins Fontes, 1997.

BIASI-RODRIGUES, B. A. A Diversidade de gêneros textuais nos livros didáticos: Um Novo Modismo? Perspectiva. Florianópolis, v. 20, n.1, p. 49-64, 2002.

BRASIL, SEF. Parâmetros Curriculares Nacionais. $3^{\circ}$ e $4^{\circ}$ ciclos do Ensino Fundamental. Brasília, 1997.

Ministério da educação. Secretaria de educação básica. Programa

Gestão da Aprendizagem Escolar - Gestar II. Língua Portuguesa: Caderno de Teoria e Prática - TP3- por Maria Luisa Monteiro Sales Coroa. Brasília, 2008.

Ministério da educação. Secretaria de educação básica. Programa

de Gestão da Aprendizagem Escolar. - Gestar II. Disponível em: www.mec.gov.br > Educação Básica > PDE GESTAR II (acesso em 11/08/2009).

FURLANETO, Maria Marta. Produzindo textos: gêneros ou tipos? Perspectiva. Florianópolis, v. 20. n. 1. p. 77-104, 2002.

MARQUESI, Sueli Cristina. O texto descritivo. São Paulo: Cortez, 1999. 
MEURER, José Luiz; MOTTA-ROTH, Desirée. Gêneros textuais. Bauru: EDUSC, 2002.

SANTA CATARINA, Secretaria de Estado da Educação e do Desporto. Proposta Curricular de Santa Catarina: Educação Infantil, Ensino Fundamental e Médio: Disciplinas Curriculares. Florianópolis, COGEN, 1998.

SANTA CATARINA, Secretaria de Estado da Educação e do Desporto. Proposta Curricular de Santa Catarina: Educação Infantil, Ensino Fundamental e Médio: Formação Docente para Educação Infantil e Séries Iniciais. Florianópolis, COGEN, 1998.

ZANETTIN, Roseli Pioli. O texto narrativo e a produção de resumos. Dissertação. São Paulo: PUC, 2006 